\title{
Indagações sobre um método acima de qualquer suspeita*
}

\author{
Doubts on a method beyond suspicion
}

\author{
Francisco Murari Pires \\ murari@usp.br \\ Professor titular \\ Universidade de São Paulo \\ Av. Prof. Lineu Prestes, 338 \\ 05058-900 - São Paulo - SP \\ Brasil
}

\section{Resumo}

Este ensaio coloca algumas indagações questionando a inconsistência da trama argumentativa porque Carlo Ginzburg concebeu os fundamentos de sua proposição do paradigma indiciário. Um primeiro movimento reflexivo dessa interpelação questionadora intriga a exploração de algumas considerações porque o espectro da bibliografia crítica avaliou a tese de Ginzburg. Consequente a ele, desdobra-se o segundo movimento porque a reflexão crítica toma por foco o eventual diálogo da proposição epistemológica de Ginzburg com o congênere conceito, originalmente tucidideano, de indiciamento (tekmérion) como procedimento metodológico de veracidade factual, diálogo este, senão totalmente silenciado, efetivamente elidido pela (des) consideração com que Ginzburg o irreleva.

\section{Palavras-chave}

Carlo Ginzburg; Tucídides; Metodologia da história.

\begin{abstract}
This essay casts some doubts on the consistency of the argumentative plot on which Carlo Ginzburg founded his evidentiary paradigm. A first moment of this reflective questioning will address the way Ginzburg's thesis was assessed by the critical literature. A second step will then focus on the interrelations between Ginzburg's epistemological considerations and the Greek notion of indictment (tekmérion), as originated in Thucydides' work. For Thucydides, as also for Ginzburg, indictment is the methodical procedure that guarantees the factual accuracy in historiography. The essay suggests that Ginzburg disregarded his dialogue with Thucydides, not simply by being entirely silent about it, but rather by eliding it.
\end{abstract}

\section{Keywords}

Carlo Ginzburg; Thucydides; Methodology of history.

\author{
Recebido em: 7/11/2013
}

Aprovado em: 16/12/2013

\footnotetext{
* O título presta homenagem à ideia do filme de Elio Petri protagonizado por Gian Maria Volonté: Indagine su un cittadino al di sopra di ogni sospetto.
} 
No meio do caminho tinha uma pedra, tinha uma pedra no meio do caminho (Carlos Drummond de Andrade).

\section{Manoel Luiz Salgado Guimarães, in memoriam: rememoração do espírito de uma conversa}

7 de setembro de 2007, sessão de encerramento do I Simpósio "Antigos e Modernos: diálogos sobre a (escrita da) História". Porque a iniciativa então inaugurada tivesse significativa marca identitária, coincidentemente prevista a realização do Evento justo na Semana da Pátria, destaque foi dado à análise da Historiografia Brasileira para que seu aporte de reflexão crítica o encerrasse. A participação de Manoel Luiz Salgado Guimarães ancorava a excelência da proposta. Ao ensejo das circunstancialidades da data, sua conferência historicizava o "debate em torno de uma história nacional no Brasil oitocentista", tendo por foco nuclear de análise o que Manoel Salgado categorizou como "textos de fundação", assim atinentes à proposição instituinte do IHGB. Em meio à sua exposição, uma referência singular a uma passagem do texto de Raimundo José da Cunha Matos ("Dissertação acerca do sistema de escrever a História Antiga e Moderna do Império do Brasil") ressoou em nosso espírito ecos que maravilhosamente reverberavam o espírito que inspirava e promovia o evento. Por uma intrigante fórmula, Cunha Matos nomeava, em conjugação figurativa de "cor local", a práxis historiográfica de estabelecimento de veracidade de textos por "o escalpelo da boa crítica" (GUIMARÃES 2008, p. 409). Uma fagulha livre em nosso espírito fez pensar alguma similaridade de irreverência com a célebre declaração provocativa de afirmação de identidade brasileira por Oswald de Andrade: "Tupy or not tupy, that is the question". Tanto mais que o deslocamento identitário promovido pelo conceito indigenista (cor)respondia com certa precisão à condizente reversão ou antídoto aos nexos da teorização original de matriz europeizante. Por um lado, a acuidade crítica da "ciência médica": operação cirúrgica a extirpar o "mal" que atacava o texto, apurando e depurando sua verdade histórica. Por outro, ainda mais (im)pertinente, podia-se aventar uma similitude com veneranda criação historiográfica de congênere matriz, esta de marca tucidideana: a crítica de veracidade categorizada por "basanizo". Em sentido primário, testar a "falsidade da moeda de ouro" pelo risco da "pedra de toque" (o basalto) que denunciasse sua "corrupção" por material vil. E também, em sentido derivado, "torturar" o escravo porque declarasse a verdade do que soubesse de um acontecimento criminoso sob investigação. Pelos (pre)conceitos do imaginário aristocrático grego antigo, o escravo, ser "inferior", era dado a mentir, (des)razão ideológica porque então se justificasse legalmente subtrair-lhe por violência a revelação da verdade a que naturalmente não estava afeito. Não só, pois, ciência médica, mas também afinidades policiais rondam a crítica de veracidade porque responde, por exemplo, a práxis historiográfica do indiciamento, o "tekmérion" originalmente tucidideano. Mas agora, pela irreverência do escalpelo, alguma aspiração porque se combata o jogo de papéis contaminado por vicissitudes históricas de passado colonial mais avatares recentes de dominação ideológica, quer de ultramar além Atlântico, quer por certo lugar no Continente ao Norte. 
Aspirações de uma Teoria da História no Brasil e do Brasil, sem descair por atavismos nacionalistas nem degenerações de ignorância xenófoba. Que Manoel Luiz Salgado Guimarães nos seja o emblema de tal espírito!

Mais de dois milênios depois de Tucídides ter proposto o indiciamento como procedimento metodológico de reconstituição dos acontecimentos passados, assim também propôs similar método um outro historiador, este, entretanto, paradoxalmente desleixando (ou escamoteando) justo a consideração desse acontecimento histórico de ponderação tucidideana.

\section{Paradigma indiciário}

Pelo último quarto do século XX adentrando a primeira década do novo milênio, Carlos Ginzburg elaborou, em uma série de artigos e ensaios, proposições de teses porque intentasse dar uma resolução a um velho dilema, algo fantasmagórico, que há bom tempo já assombra a (des)confiança na história: comporta essa modalidade de conhecimento respeitante aos modos porque atuam os homens no mundo diferenciados e específicos fundamentos metodológicos que lhe assegurem singular estatuto de (alguma) cientificidade? A atualidade do velho dilema vinha de ser (re)ativada pelos então recentes ares epistemológicos pós-modernistas que instigaram atualizadas intrigas de mazelas querelantes. Intrigas agora mais graves porque, ao que argumentaram Arnaldo Momigliano e Carlo Ginzburg na sua esteira, insuflavam teses de revisionismo histórico, especialmente agudas por (re)avivarem as chagas do holocausto em renhidas disputas e debates por quem ideologiza preservar a realidade viva dessa memória contra quem ideologiza, em contrapartida, dissipar o espectro oportunista de sua (cor)respondente politização; uns a promover a visão horrorizada daquele fenômeno em estigma da II Guerra Mundial, outros a cegarem. Como se a questão fosse, ao que induz a peroração de Carlo Ginzburg contra os por ele ditos "céticos relativistas", ditar o imperativo de que a todo historiador se impõe o dever de decidir qual o certo, qual o errado, quem virtuoso, quem vicioso: "pós-modernismo por história-literatura-ficção x modernismo da história de (in)certa cientificidade" ... "Ginzburg x Derrida" ... "Momigliano x Hayden White" ... e ainda politizações de "sionismo x revisionismo histórico"? A perversidade do procedimento assim reclamado descai ${ }^{1}$ por imperativo (alegado como de ordem moral ou ética) maniqueísta de quem proclama falar em nome de alguma ciência e da verídica realidade factual porque se arvora a nos impor mais outro mandamento, agora historiográfico, como se dez já não nos bastassem!

No ensaio que inaugura a investida reflexiva de Ginzburg - Sinais: raízes de um paradigma indiciário (GINZBURG 1989, p. 143-179) -, o historiador busca identificar o procedimento metodológico que, mais especialmente conceitualizado no domínio das "ciências humanas" na modernidade (fins do século XIX a inícios do XX), atravessara e acompanhara como práxis investigativa toda a história humana, tendo suas raízes em tempos primordiais, desde as 
sociedades de caçadores do Neolítico. Tal modalidade de atuação inquiridora, ao que argumenta Ginzburg, perpassa inúmeros campos da atividade humana: perseguições de caça, artes divinatórias, práticas médicas, imaginários literários de romances policiais e detetivescos, perícias eruditas de "connoisseurs de obras de arte", saber psicanalítico freudiano, técnicas grafológicas, exegese de crítica textual histórico-filológica, vindo a alcançar, ainda, os procedimentos burocráticos de identificação do indivíduo na sociedade burguesa contemporânea. Reconhece-se, assim, ao longo de toda essa história, o paradigma epistemológico que lhe corresponde sob distintas nomenclaturas: ou "indiciário" ou "venatório" ou "divinatório" ou "semiótico".

Enquanto categoria de discurso epistemológico, o paradigma decantara conceitualmente, ao que detecta a análise de sua gênese por Ginzburg, pelo findar do século XIX (GINZBURG 1989, p. 143), então articulado em três agenciamentos sucessivos, senão mesmo conexos. Primeiro, entre 1874 e 1876, por Giovanni Morelli (sob o pseudônimo de Ivan Lermolieff) em "proposta de método" por que intentava regrar procedimentos de análise de quadros capazes de identificar a autoria dos mesmos por meio do reconhecimento de detalhes pictóricos reveladores de traços idiossincrásicos de determinado pintor (GINZBURG 1989, p. 143-145). A seguir, por Conan Doyle por fins dos anos 1880 (GINZBURG 1989, p. 145-146), que operava o paradigma na criação de suas novelas detetivescas, figurando-o pela arte indiciadora de crimes porque primava a arguta perícia de Sherlock Holmes. E também por Sigmund Freud em torno de 1898 a 1901, quando arquitetava os fundamentos da técnica psico-analítica de "desvendar segredos e verdades ocultas a partir de resíduos negligenciados", de que o método morelliano, ao que o próprio Freud apontou anos depois, provera-Ihe manancial inspirador (GINZBURG 1989, p. 146-149).

Por todos os três, ao que ajuíza Ginzburg, perpassa a mesma proveniência fundamentadora do método paradigmático: "o modelo de semiótica médica de alcance diagnóstico" que identifica a doença por meio do (re)conhecimento perspicaz de "traços ou pistas infinitesimais" que, desconsiderados senão negligenciados pelo olhar comum como "triviais, superficiais, irrelevantes ou insignificantes", não obstante indiciam "a realidade patológica oculta, inapreensível pela observação direta" que a perde porque extraviada, desatenta daquele preciso foco extraordinário de percepção tão inteligente quão (im) pertinente. Modelo de metodologia médica que, por sua vez, supunha e remetia, precisamente na década de 1870-1880, diz Ginzburg, ao "paradigma indiciário que então se afirmava no horizonte das ciências humanas baseado justamente na semiótica" (GINZBURG 1989, p. 150-151).

Apreciando a conjugação cumulativa das operações definidoras do paradigma indiciário por Morelli, Sherlock Holmes mais Freud, Ginzburg (re) compõe o complexo de atributos que caracterizam sua distintiva natureza, conferindo-lhe identidade metodológica. Jogos de contraposições marcam a ambígua (des)qualificação da natureza do indício (traços, pistas) enquanto objeto que embasa o método por axiologia de revertida hierarquia (historiográfica): pequeno ou minúsculo (mesmo infinitesimal) versus grande; detalhe versus 
importante; trivial versus fundamental; parte versus todo; individual versus social; menosprezado versus eleito; restos versus proveito; baixo versus alto; inferior versus superior; marginal versus central; oprimido versus poderoso; tangível, concreto versus imaterial, formal; opaco versus transparente; observável versus invisível; manifesto versus oculto; evidente versus latente; ciente versus inconsciente; reprimido versus idealizado, sublimado; superficial versus profundo; subterrâneo versus celeste; trevoso versus brilhante; infernal versus divino. Jogo expresso em retórica de paradoxos ambíguos porque se proclama a capacidade cognitiva de método eficiente em detectar, alcançar e apreender a realidade histórica maior a partir da menor. ${ }^{2}$

O motto virgiliano da Eneida em epígrafe do tratado freudiano emblematiza tal retórica de definição do mét-hodos dizendo a via ou caminho porque essa categoria epistemológica responde por sua própria etimologia definidora: Flectere si nequeo Superos, Acheronta movebo. ${ }^{3}$ Uma nomenclatura conceitual, transitando dos antigos aos modernos, divinatio, especialmente articula as virtudes singulares dessa modalidade metodológica de conhecimento que opera por indiciamento na reconstituição de realidade histórica factual apurada e depurada por argumentos de veracidade.

\title{
Detalhes
}

A epígrafe com que Ginzburg encima a reflexão do ensaio Sinais por que aponta o sentido sintético de seu alcance cognitivo diz: "Deus está nos detalhes" (GINZBURG 1989, p. 143). Marco Bertozzi, em comentário ao ensaio de Ginzburg, contrapõe-Ihe o aforisma atribuído a Karl Kraus que reconhecia que "nos detalhes, é o diabo que se esconde". Pelo que Bertozzi nos adverte:

\begin{abstract}
Mas ao entrar nos detalhes, corremos o risco de ser o joguete de algum pequeno diabo divertindo-se às nossas costas. Nossos ancestrais diziam, quando alguma coisa escapava de suas mãos e não conseguiam agarrá-la: Olhe! É o diabo que joga... A investigação é cansativa, não chegamos sempre ao final na primeira tentativa. Os detetives e os sábios, na busca do culpável, na busca da verdade relativa à sua investigação, enroscam-se com frequência em falsas pistas: a presa não se deixa facilmente ser apanhada (BERTOZZI 2007, p. 29). ${ }^{4}$
\end{abstract}

Que seja! À caça indiciária do diabo pela trilha de (alguns) detalhes ginzburgianos!

\footnotetext{
${ }^{2}$ Não deixa de ser irônico que a pretensão de operar a interpretação mais axiologia metodológica proclamando-a pela hierarquia invertida a assim apreender a história pelo lado do "baixo", "inferior", "marginalizado" como o declaram as proposições ginzburgianas tenham encontrado estranhamentos, senão rejeições, justo da parte dos agentes e sujeitos mesmos que ativam as razões dos oprimidos: vejam-se as manifestações do revolucionário mais as da feminista a esse respeito, plenas naquele e parciais nesta, ambas integradas no artigo de Stephanie Jed (JED 2001, p. 372-384).

3 "Se não posso mover os deuses superiores, moverei o Acheronte".

${ }^{4}$ No original: "Mais en entrant dans les détails, nous risquons à notre tour d'être le jouet de quelque petit diable aimant à se moquer de nous derrière notre dos. Nos ancêtres disaient, quand quelque chose leurs filai des mains et qu'ils ne parvenaient pas à l'attraper: Regardez! c'est le diable qui joue ... L'enquête est fatigante, on ne parvient pas toujours au but du premier coup. Les détectives et les savants, qui dans la recherche du coupable, qui celle de la vérité relative à leur enquête, s'embrouillent souvent dans de fausses pistes: la proie ne se laisse pas facilement piéger".
} 
Há algo de ilusionismo oportunista senão mistificação protéica ${ }^{5}$ que transparece das argumentações discursivas com que Ginzburg trama as intrigas de suas teses, espécies de (dis)simulados icebergs de que se mostram apenas a ponta visível acima da água, ${ }^{6}$ a vagar soltos, desgarrados da geleira narrativa da micro- porque atravessem o oceano epistemológico da história.

Peter Burke comentando em resenha a Miti, emblemi, spie a vasta bibliografia mais extensas temáticas que alimentam o livro, aponta algo sucintamente: "Ginzburg é um leitor voraz" (BURKE 1990, p. 108). Desse ambíguo cumprimento por que se saúda o historiador italiano a aludir quer à sua sede de conhecimentos quer à pressa com que avidamente os sorve, dizem similarmente outros comentadores por formulações de críticas algo ambiguamente (dis)simuladas. O próprio Burke acresce: "os leitores são levados a acabar cada ensaio com a cabeça repleta de questões não respondidas" (BURKE 1990, p. 110).7 Assim também o faz David Herlihy: "os ensaios têm um alcance tão vasto, são tão ricos e provocativos, que uma revisão completa acabaria por ser mais longa que o próprio livro" (HERLIHY 1991, p. 502). ${ }^{8}$ Já Tony Molho dá sinais críticos mais claros: "gostaríamos que Ginzburg tivesse adicionado algumas páginas a mais a fim de clarificar os obscuros, ainda indefinidos aspectos de sua formulação. Ele aventurou-se nessa questão em incursões posteriores. Mas, se formos julgar pelas respostas de alguns de seus críticos, não o fez satisfatoriamente" (MOLHO 2004, p. 137). ${ }^{9}$ E Perrine Simon-Nahum refere já a idiossincrasia como estigma das leituras: "Carlo Ginzburg despeja um saber que não pertence senão a ele, ousando analogias e ligações cujos detalhes fortuitos mascaram a erudição prodigiosa sobre a qual repousam" (SIMON-NAHUM 2011). ${ }^{10}$ Ambíguos cumprimentos que ponderam a conjugação "virtuosa/viciosa" com que Ginzburg argumenta proposições reflexivas tão ricas de desafios quão insatisfatórias de (des) entendimentos.

Mais contundentemente o ajuíza James Elkins:

\footnotetext{
${ }^{5}$ Emblemático o parágrafo no prefácio do livro Sinais em que, apresentando espécie de mimesis de daimon socrático dada à guisa de argumento, o Autor intriga (con)fusão de (ir)reflexão (dis)simulada de autocrítica com sua negligência (GINZBURG 1989, p. 10-11).

6 Para indicações das partes submersas que descobrem as insuficiências mais deficiências pontuais das argumentações de Ginzburg porque se possa suprir aquelas e concertar estas, confiram-se: VEGETTI 1980, p. 8-10; VATTIMO 1980, p. 23-24; ROVATTI 1980, p. 36-37; VALERI 1982, p. 141-143; HARTOG 1982, p. 25; LaCAPRA 1985, p. 45-69; BURKE 1990, p. 108, 110; DUMÉZIL 1985, p. 985-989; ZAMBELLI 1985, p. 983999; BLACK 1986, p. 67-71; CARRIER 1987, p. 76-77; BARTLETT 1991; MARTIN 1992, p. 613-626; SCHUTTE 1992, p. 576; STRUEVER 1995, p. 1203; BUTTI de LIMA 1996, p. 8-9; UZEL 1997, p. 28, 31-32; EGMONDMASON 1999, p. 241, 244-245, 247-250; AYA 2001, p. 151-152; JED 2001, p. 372, 373-374; COHEN 2003, p. ix; HARTOG 2005, p. 228-229; BORGHESI 2006, p. 110-111, 114, 118-119, 121-126; THOUARD 2007, p. 12-13, 16-17; BERTOZZZI 2007, p. 33; MOST 2007, p. 63, 65, 67-68, 70, 73; HAMOU 2007, p. 190-194; COHEN 2007, p. 222-223; DOJA 2007, p. 93-94); PAPE 2008, p. 1; OGAWA 2010; SIMON-NAHUM 2011, p. 2; VOUILLOUX 2011, p. 2-3, 4, 6, 7-8, 9-10; RANCIÈRE 2011, p. 474-484; HARTOG 2011, p. 540-552; BOULAY 2011.

7 No original: "Readers are likely to finish each essay with their heads full of unanswered questions. If such abundance is a fault, it is one which is all too rare in historical writing today".

${ }^{8}$ No original: "The essays are so far-ranging, so rich, and so provocative that a full review would likely be longer than the book itself".

${ }^{9}$ No original: "One wishes Ginzburg had added a few more pages to clarify the dark, still undefined sides of his formulation. He ventured into this issue in subsequent forays. But, if one were to judge by the response of some of his critics, he did not do so satisfactorily".

10 No original : "Carlo Ginzburg déaploie un savoir qui n'appartient qu'à lui, osant des analogies et des rapprochements dont les dehors fortuits masquent la prodigieuse érudition sur laquelle elles reposent".
} 


\begin{abstract}
Existem muitos problemas neste ensaio, o qual tem sido, ao mesmo tempo, muito usado e pouco criticado; podemos questionar a sufocante voz autobiográfica ao longo do ensaio, na qual o autor implícito torna-se ele mesmo um 'detalhe desprezado' e seus trabalhos tornam-se mais exemplos inconscientes do método "baixo" do que propriamente aplicações controladas dele; e somos levados a querer indagar sobre o sentido da curiosa, não científica tentativa de Ginzburg em excluir do domínio da ciência o que ele descreve como a intenção de observar sem teorizar (ELKINS 1996, p. 279-280). ${ }^{11}$
\end{abstract}

Por quais alternativas de prediletas exemplificações de indiciamento na reconstituição de fatos avança a argumentação por que Ginzburg (com)prove sua efetividade operacional? Pelos inúmeros indiciamentos bibliográficos referidos por Ginzburg, alguns especiais relatos ilustram a maravilhosa eficiência do método indiciário em revelar a verdade, todavia oculta, de um acontecimento passado, justo apenas a inferindo a partir da concatenação das pistas e indícios subsistentes.

Assim o conto dos Três príncipes de Serendip que, ajuizando com argúcia e perícia de discernimento o complexo de marcas deixadas pela trilha de um animal ao longo da estrada, são capazes de descrevê-lo com precisão rigorosa de detalhes apesar de jamais o terem visto: um camelo coxo (pelas marcas de passos de três patas nítidas contra apenas uma outra arrastada), cego de um olho (pela falta de grama por ele comida apenas de um dos lados da estrada, entretanto ali menos verde), falto de um dente (pelas bolotinhas de grama semimastigada deixadas cair da largura de um), levando uma mulher (pelas marca 30 de um calçado associadas às de um camelo ajoelhado deixadas junto a uma poça de urina feminina identificável por odor mais gosto) grávida (pelas marcas de mãos ao lado da poça porque apoiasse o esforço de se levantar) mais cargas de mel de um lado (pelas moscas atraídas para uma borda da estrada pelo que ali respingara) e de manteiga de outro (pelas formigas para a outra) (MÉSSAC 2011, p. 37-46). Similarmente ocorre em um dos contos integrados por Voltaire em Zadig, certamente inspirado nos originais orientais, com o decifrador de pegadas animais agora conseguindo reconhecer a passagem ou de uma cadela ou de um cavalo, por ele então descritos em minúcias e detalhes, não obstante jamais tê-los visto.

Tem-se por tais contos, acrescenta Ginzburg, a origem ou embrião das novelas policiais que narram histórias de crimes misteriosos maravilhosamente descobertos por engenhosos detetives, tais como Dupin, na criação de Edgar Allan Poe, e sobretudo Sherlock Holmes, pela de Conan Doyle, este último justamente figurando como uma das instâncias reflexivas porque se decanta a formulação conceitual do paradigma indiciário por fins do século XIX.

Sim, certamente, nenhum dos três príncipes de Serendip nem Zadig haviam visto anteriormente e por isso conheciam ou aquele camelo ou aquela cadela

\footnotetext{
${ }^{11}$ No original: "There are many problems with the essay, which has arguably been overused and undercritiqued: one might question the stifling of the autobiographical voice throughout the essay, so that the implied author himself becomes a "despised detail" and his works become unreflective examples of the "lower" method rather than controlled applications of it; and one might want to inquire into the meaning of Ginzburg's curious, unscientific attempt to exclude from the domain of science what he describes as the intention to observe without theorizing".
} 
que tão maravilhosamente descreveram em abundantes detalhes. Tampouco Sherlock Holmes presenciara os crimes que tão inteligentemente descobre. E, no entanto, assim se representa ficcionalmente apenas o que o autor desses contos e histórias de princípio sabia plenamente, tendo imaginado ou a visão daqueles animais ${ }^{12}$ ou o presenciamento destes crimes, de que a configuração de atos e decisões cognitivas atribuídas a seus personagens confunde a ilusão. Pois, se Zadig não viu a cadela e o cavalo, Voltaire os viu, já que os (re)criou. ${ }^{13} \mathrm{E}$ se Sherlock não testemunhou o crime, Conan Doyle ${ }^{14} \mathrm{o} f e z$, tendo-o imaginado.

Ginzburg ilude por demonstração comprovadora da eficiência metodológica do paradigma indiciário, decifrador de realidade factual, a razão invertida da operação lógica implicada: dá por inferência conclusiva do acontecimento passado supostamente desconhecido, operada por meio da concatenação dos indícios identificados como o que dele restou e existe presentemente manifesto, o que é tramado por intriga de decomposição em indícios produzidos a partir do acontecimento ficcionalmente dado e conhecido de início, de modo que aquela inferência conclusiva de apreensão do acontecimento reconstituído reduz sua validade lógica a uma tautologia. Não há equivalência de transitividade lógica entre as duas vias, pois o todo é mais do que a soma das partes por supor justo a modalidade de razão ou nexo que as estrutura univocamente ou que, pelo contrário, as desestrutura pluralmente. E a decomposição em indícios dispõe pluralidade de concatenações de versões de diferenciadas semânticas de percepção (re)constituidora. ${ }^{15}$

Os exemplares de indiciamentos configurados por esses contos orientais ${ }^{16}$ em que se fundamenta a argumentação de Ginzburg comportam a natureza fantasiosa correspondente às obras de relatos maravilhosos que os integram. Eles se ordenam na estruturação narrativa do conto por um gradiente progressivo de fantasias que imaginam (ir)realidades (menos ou mais) maravilhosas tendo por desígnio simular provas de (menor ou maior) perspicácia com que se defrontam e resolvem a inteligência e perícia superlativa dos protagonistas a, pois, apresentá-los por estatura heroica. Num primeiro nível mais elementar de nexos indiciários se os escalonam quer pelas formas distintivas de pegadas das patas (do camelo ou do cavalo ou da cadela), quer dos gêneros de alimentos por eles preferidos (gramíneas para camelos, açucarados para moscas, gordurosos

\footnotetext{
${ }^{12}$ Aliás diversamente (re)criados de modo a conjugar diferenças de indícios assinalados conforme as variantes dos contos narrados correspondentes aos nexos imaginativos que distinguem cada versão (MÉSSAC 2011, p. 37-46).

${ }_{13}$ Afinal, alguém viu o animal (na origem cognitiva da codificação categorizadora de suas pegadas) pois quem seria capaz de identificar pegadas de animal que jamais foi visto?

${ }^{14}$ A (con)fusão Sherlock Holmes por Conan Doyle é ou indireta ou alusivamente apontada já pelos comentários de Marcelo Truzzi: "a grande maioria das inferências de Sherlock não resiste a um exame lógico. Ele as conclui satisfatoriamente pelo simples motivo que o autor das histórias o permite" (1991, p. 79) e de Umberto Eco: "Como ele [Sherlock Holmes] tem o privilégio de viver em um mundo construído por Conan Doyle que, adequadamente, se encaixa em suas necessidades egocêntricas, então, ele não carece de provas imediatas de sua perspicácia" (1991, p. 241). Considere-se ainda o que diz Umberto Eco sobre a estrutura teleológica do juízo operado por Zadig ao partir do princípio de que os dados indiciários em que se baseia "fossem harmoniosamente relacionados" (ECO 1991, p. 236), assim os sendo justo pela decisão criativa de Voltaire.

15 Emblemático nesse sentido a reflexão proposta em Rashomon de Akira Kurosawa/Ryunosuke Akutagawa. Confira-se ainda a crítica que Robert Bartlett dirige ao "método associacionista" de "alegados indícios" operado por Ginzburg em "Ecstasies" (BARTLETT 1991).

${ }_{16}$ Confiram-se os relatos apresentados por Roger Méssac (2011, p. 37-46).
} 
para formigas), quer de alguns de seus distintivos modos de comportamento (o espalhamento das fezes pela cauda na defecação do camelo contra sua concentração em bloco na do boi). Tais são os tipos de indícios a que se apegam as argumentações quer de Méssac, quer de Voltaire, e nessa esteira também Ginzburg, assim redutoramente condizentes com o foro de racionalidade factual mais plausível ${ }^{17}$ porque as conjecturas divinatórias ganhem aspecto comprovatório de realidade. Pois, eles silenciam, elidem o prosseguimento da história memorizada pelos contos orientais, as quais progridem aventando indiciamentos bem mais audaciosos e inauditos: a vinha (ou o trigo) plantada sobre um sepulcro de que fora fabricado o vinho (ou o pão) porque seu gosto inspira pensamentos fúnebres; o cordeiro que foi amamentado por uma cadela porque sua carne tinha tal paladar, ou o cabrito assim aleitado porque sua carne concentrava o depósito de gordura junto ao osso; o sultão que não passa de um bastardo, filho de pai escravo e mãe adúltera, porque afeito a comportamento indigno de bisbilhotar escondido as conversas de seus hóspedes.

Contos maravilhosos enquadrados, pois, por contextualizações tópicas de histórias de sucessão régia porque se memorizava a ideologia antiga de legitimação do poder monárquico, figurando as virtudes e méritos superlativos do rei porque herói. Memórias históricas que afirmam a arte da divinatio por sobreposições cumulativas de registros literários e científicos que as acompanham ao longo dos séculos de seu percurso pela história da civilização humana, assim configurando códigos categorizadores de indiciamentos. Percurso, pois, milenar, 32 porque a disponibilidade do nosso método indiciário encontra-se bem longe de qual remota origem paleolítica o tivesse inaugurado. Que o método, então, remeta à perspectiva do olhar da história pelo lado social inferior, marginal ou oprimido operando por intuição baixa contraposta à alta, científica, responde antes pelos vezos da retórica ilusionista ginzburgiana, seja lá a qual fantasia de oportunismo ideológico ela satisfaça. ${ }^{18}$

Condizente com a metodologia da microhistoria ${ }^{19}$ de que Ginzburg figurava como seu proponente mais famoso e destacado, a formulação do paradigma indiciário tanto a fundamenta em termos mais imediatos de proposição de uma disciplina historiográfica particular, quanto almeja conferir-lhe alcance de projeção modelar porque se generalize por essa modalidade de método a distintiva virtuosidade cognitiva da história. Figuração metodológica especialmente apropriada para o conhecimento histórico que arvora capacidade de compor discurso assegurado por modos argumentativos estruturadores de declarações providas de referencialidade factual. E, todavia, da casuística ampliada e extensa porque Ginzburg mapeia o espectro empírico comprovador da realidade histórica do paradigma, percorrendo assim praticamente todo o percurso da história humana, a indicação do procedimento particularmente

${ }_{17}$ Confira-se o comentário de Méssac (2011, p. 39).

18 Confira-se, similarmente, a crítica de Dominick LaCapra ao livro de Ginzburg (O queijo e os vermes), introduzida por alusiva referência ao "methodological populism" como uma tendência presente em variantes da historiografia dos anos 1980 (LACAPRA 1985, p. 45-69).

${ }^{19}$ Os nexos que imbricam o ensaio "Sinais" com as proposições da microhistória são apontados pelo próprio Ginzburg no texto de 2007 "Refléxions sur une hypothèse vingt-cinq ans après" (GINZBURG 2007, p. 37-47). 
experienciado no domínio próprio da escrita da história, que não esse singular hors concours da microhistória, não se encontra pelo ensaio do historiador italiano qualquer evidenciamento exemplificador. Tanto mais paradoxal lapso por elipse ou esquecimento que, entretanto, as pistas aproximadoras de suas lembranças afloram pelos argumentos então explorados.

Peter Burke, em singular declaração de crítica expressa ao ensaio de Ginzburg, estranha que ele dê a "divination" como sendo "o método" da práxis historiográfica, quando antes apenas constitui um de seus procedimentos operacionais. ${ }^{20}$ O comentário de Harry C. Paine aponta na mesma direção pois, ao se referir à especificidade operacional da divinatio em termos de "instinct, insight, intuition", assimila o conceito pela ideia de gênio como era definida por fins do século XVIII. ${ }^{21}$ O que Payne assim alude apenas em termos genéricos, comporta identificação mais precisa e singularizada, pois foi precisamente como divinatio que Barthold Georg Niebuhr, ${ }^{22}$ por inícios do século XIX, nomeou sua proposição de método histórico-filológico enquanto fundamento de uma história de pretensão científica. A mesma nomenclatura comparece igualmente em Leopold von Ranke ainda por essa mesma época. Em ambos, Niebuhr e Ranke, a instância modelar por que respondesse a proposição do método histórico, qual seja, Tucídides, é justamente figurada como "o gênio" da história.

Já François Hartog aproximara a tese metodológica de Ginzburg da de Ranke, reconhecendo no desígnio factual da concepção de história do primeiro ecos seculares do famigerado lema que imortalizou o segundo: zeigen wie es eigentlich gewesen. Despistamentos de ressonâncias historiográficas ainda mais antigas, milenares mesmo, se denunciam agora pela fórmula de álgebra elementar com que Ginzburg reitera, em texto de 1991, a profissão de fé no aporte realista da história que tem por vocação decidir os fatos ocorridos:

Podemos concluir, então, que a tarefa tanto do juiz como do historiador implica a habilidade de demonstrar, de acordo com regras específicas, que $X$ realizou $Y$, onde $X$ pode designar $o$ ator principal, ainda que não nomeado, de um evento histórico ou de um ato legal, enquanto $Y$ designa alguma forma de ação (GINZBURG 1991, p. 84-85). ${ }^{23}$

\footnotetext{
20 "No seu aspecto crítico, o autor deixa para si mesmo muito pouco espaço para refinar seu contraste básico entre dois modos de investigação - sua visão implícita 'do' método científico borra as distinções entre experimentadores, observadores, entre outros, assim como não considera a possibilidade de que o que ele denomina "divinação" é um elemento presente em toda pesquisa séria, mais do que 'o' método de pesquisa em determinados campos". No original: "On the critical side, the author allows himself too little space to refine his basic contrast between two methods of inquiry- his implied view of "the" scientific method blurs the distinctions between experimenters, observers, and so on and does not allow for the possibility that what he calls "divination" is an element in all serious research, rather than "the" method of research in some fields" (BURKE 1985, p. 109).

21 "A única saída que ele encontra é um sistema que vincula de algum modo 'instinto, insight, intuição', através dos quais quer significar um processo não distinto de algumas definições oitocentistas do gênio, isto é, a recapitulação iluminada de um processo racional". No original: "The only way out, he finds, is a system that relies to some extent on "instinct, insight, intuition," by which he means a process not unlike some eighteenthcentury definitions of genius, that is, "the lightning recapitulation of rational processes" (PAYNE 1992, p. 1176). 22 Confira-se: MURARI PIRES 2012 (no prelo).

23 No original: "We can conclude, therefore, that the tasks of both the historian and the judge imply the ability to demonstrate, according to specific rules, that $x$ did $y$, where $x$ can designate the main actor, albeit unnamed, of a historical event or of a legal act, and y designates any sort of action".
} 
O que temos aqui se não o travestimento da célebre definição aristotélica da história em oposição à poesia, apenas transmutando em incógnitas genéricas " $x$ " e " $y$ " o que o filósofo declarara nominalmente: "o que Alcibíades fez ou experienciou"? Mas as ponderações aristotélicas suscitadas pela Poética, Ginzburg as evita, escamoteia em sua argumentação preterindo-as pelas da Retórica, assim operando um esquecimento de referência analítica que justamente estorvaria a consecução de seu próprio argumento. ${ }^{24}$

Ora, por aquele dístico emblemático Ranke pondera similar aporte cognitivo ao que é referido por Ginzburg como marca de Aby Warburg, com o historiador alemão em 1824 definindo sua proposição de escrita da história em termos de apenas "dizer [mostrar] como realmente ocorreu". Mas o que em Ranke era profissão de fé luterano-pietista, em Ginzburg não se sabe como (des)qualificar em termos de (des)crença em Deus, ao que se pode apreciar por informe de entrevista em que ele antes diz de (in)certo ateísmo. ${ }^{25}$

Elisões historiográficas no ensaio sobre Sinais tanto mais surpreendentes quando Ginzburg desconsidera a contribuição de Tucídides que justamente operara o indiciamento em suas reconstituições respeitantes ao passado histórico na assim dita Arqueologia de sua História. Lapso algo estarrecedor por não se tratar de ignorância ou desconhecimento, já que referida a lembrança tucidideana, todavia marginalizada, em nota-de-rodapé, por assim ambígua (des)lembrança que (des)considerassesse sua (ir)relevância enquanto instância de contribuição reflexiva sobre o paradigma

Lembrança mesmo (im)pertinente por interpelação inaugurada já no nascedouro do ensaio, então formulada por Luciano Canfora no debate promovido em Milão no ano de 1980. Afinal, inquiriu Canfora a Ginzburg: como traduziria ele o tekmérion tucidideano? ... "indício" ou "prova"? Pergunta capciosa! Pouco depois, mais dois anos (1982), François Hartog também estranha o silêncio de Ginzburg: "podemos nos surpreender que C. Ginzburg, em seu artigo 'Sinais: traços, pistas, raízes de um paradigma indiciário' não se atenha, no que diz respeito à Grécia, a Tucídides" (HARTOG 1982, p. 25). ${ }^{26}$ Pelo que prossegue o comentário de Hartog agora acrescendo alusão algo (des)velada quanto à (in)conveniência porque (não) respondesse o silêncio ginzburgiano: "entendendo-se que, para Tucídides, o conhecimento por indício é fundamentalmente insatisfatório". ${ }^{27}$ A crítica retorna em texto recente em que Hartog novamente aponta as inconsistências da (des)leitura ginzburgiana de Tucídides, nestes termos estabelecendo o contraponto apreciativo do movimento intelectivo que promove a dita "Arqueologia" do historiador ateniense: "vai-se do presente ao passado (inferior), revelando um modelo de inteligibilidade que depende

\footnotetext{
${ }^{24}$ A questão foi já incisivamente marcada por François Hartog (2011, p. 546-550). Em obra anterior também a assinalamos ao analisar o diálogo justo contra a Poética porque Lorenzo Valla elabora sua apreciação da escrita da história (MURARI PIRES 2007, p. 210-217).

${ }^{25}$ Confira-se a resenha de Harry C. Payne (1992, p. 1176).

26 No original: "On peut s'étonner que C. Guinzburg, dans son article 'Signes: traces, pistes, racines d'un paradigme de l'indice', ne s'arrête pas, à propos de la Grèce, à Thucydide".

27 No original: "Étant entendu que pour Thucydide la connaissance par indice est fondamentalement insatisfaisante".
} 
mais de uma teoria do poder do que de uma história antiquária" (HARTOG 2011, p. 549). ${ }^{28}$

Vinte e cinco anos depois (2005), quando do colóquio promovido pela universidade de Lille em comemoração do já um quarto de século de repercussões do ensaio original, Ginzburg (re)ativa a memória porque agora ensaiasse (o arremedo de) sua resposta, tendo-a encontrado nos ensaios que compõem a coletânea de History, Rhetoric, and Proof, The Menahem Stern Jerusalem Lectures (GINZBURG 2007, p. 39-40). Ambíguo despiste de (não) resposta tão sinuosa quão escorregadia que oscila a (des)dizer, interpelado acerca de Tucídides, o que por Flaubert é exemplificado, de modo a então generalizar em (con)fusão as respectivas declarações porque (todos) os indícios sejam provas!

Pois, por quais teores argumentativos Ginzburg constrói os nexos de sua tese que projeta o paradigma indiciário como desdobramento de metodologia historiográfica que articula em termos da categoria retórico-aristotélica da prova as concepções de Tucídides às de Lorenzo Valla?

\section{Valla tucidideano}

A Retórica de Aristóteles, mediada por Quintiliano, deu a Valla a oportunidade para escapar das limitações da retórica ciceroniana. Não por acaso, em 1448, Valla começou sua tradução de Tucídides, um historiador que Cícero desprezou por sua obscuridade, apontando-o como um modelo negativo a ser evitado pelos oradores (GINZBURG 1999, p. 64).29

Nesses termos, Carlo Ginzburg encerra seu argumento porque aproxima Lorenzo Valla de Tucídides, especialmente marcando os nexos de afinidades que solidarizam suas respectivas concepções de história.

A aproximação não era nova, fora feita já bem antes de Ginzburg, então aventada por outros críticos. Justamente, a intriga maior porque vários comentadores assim associaram os nomes de Valla e Tucídides tem por ação catalisadora a respectiva fama de ambos, tidos como fundadores do método de crítica histórica de veracidade factual.

Para Valla, a obra que especialmente o qualifica nesse sentido é a Declamatio de falso credita et ementita Constantini Donationae, quando o humanista romano teria inaugurado modernamente os fundamentos da crítica exegética averiguadora da autenticidade dos documentos históricos por meio de ajuizamentos de racionalidade filológica. O ensaio compunha contundente refutação das pretensões papais firmadas pela Doação de Constantino, desacreditando seu alegado fundamento histórico. Pelo texto mesmo se denunciavam teores espúrios e desígnios fraudulentos: anacronismos, quer de latim degenerado a acusar medievalidade bárbara, quer de ignorância histórica a apontar rudezas de "um asno", mais várias ordens de incoerências,

\footnotetext{
${ }^{28}$ No original: "on va du présent vers le passé (inférieur), em déployant un modèle d'intelligibilité qui relève plus d'une théorie de la puissance que de I'histoire antiquaire".

29 No original: "Aristotle's Rhetoric, mediated by Quintilian, gave Valla the opportunity to escape from the limitations of Ciceronian rhetoric. It is not by chance that in 1448 Valla started his translation of Thucydides, a historian whom Cicero had despised for his obscurity, pointing to him as a negative model for orators to avoid".
} 
contradições e equívocos a revelar rudimentariedade "estúpida". Conjugando recursos de artes retórica e filológica, por argumentações de plausibilidade mais de evidenciação e prova, o texto de Valla realizava obra de crítica solidária dos desígnios de patronato político porque seu discurso precipuamente respondia: secretário e historiador real de Afonso de Aragão, rei de Nápoles, desde 1435 a 1448, a Declamatio tinha alvo bem mirado, cortando as raízes da (forjada) legitimação com que o Papado fundava suas pretensões ao poder secular.

Em texto datado de 1921, Wilamowitz reconhecia inspiração tucidideana na origem da práxis historiográfica de Valla, dando-a por constatação óbvia e imediata, que não reclamava de sua erudição maior exame, razão porque a afirmou peremptoriamente: Valla "descobrira a falsificação da Doação de Constantino" apenas sob os efeitos do "contato com Tucídides", assim impregnado, como que por osmose, por seus critérios de juízo histórico. 0 equívoco da tese, entretanto, foi apontado por Rudolf Pfeiffer, que nela acusou a grosseira inversão cronológica em que incidira o célebre filólogo germânico: a Declamatio data de 1440, ao passo que a tradução de Tucídides lhe é posterior em oito anos, iniciada em 1448 (PFEIFFER 1976, p. 39). Ainda no entender de Pfeiffer, também as lógicas de racionalidade crítica de um e outro, Tucídides e Valla, operariam em termos de categorias conceituais diferentes enquanto fundamentação de sua razão crítica: ao passo que o ateniense baseava seu juízo em "cuidadosas inferências derivadas de comparações, eikazei, que reclamam tekmeria e semeia, 30 Valla obra sua análise fundamentalmente por meio de 36 argumentos linguísticos, consoante o mesmo "método empregue em seus outros escritos", que "um mundo de diferenças distancia do de Tucídides".

Uma vez acertada a cronologia que antes vitimara Wilamowitz, outros críticos renovaram argumentos insistindo na mesma tese porque se vinculassem preceitos metodológicos tucidideanos na base da modalidade de crítica histórica formulada por Valla. Edmund B. Fryde a insinua, ao lembrar que "Valla admirava enormemente Tucídides, por ele associado a Salústio como exponente de uma visão política madura" (FRYDE 1983, p. 28). Giacomo Ferraù, seguido por Marianne Pade (PADE 2000, p. 256), a aventa mais claramente, apontando a "congenialidade entre o historiador grego e o pensamento do humanista romano no que tange ao método histórico". Nestes termos Ferraù argumenta tal nexo tucidideano atuante "na concepção historiográfica de Valla" firmada nos Gesta Ferdinandi Regis Aragonum (FERRAú 1986, p. 270-1).

Pelo paralelismo metodológico estabelecido entre Valla e Tucídides, Ferraù diz da

acuidade e da seriedade dos procedimentos na escrita da história, não somente enucleada sob a vertente da qualificação técnica, mas que ainda desemboca em uma firme reivindicação da autoridade moral de que o historiador deve ser o portador, na fundamental capacidade de escrever sine ira et studio.

\footnotetext{
${ }_{30}$ Para o e exame dessa questão, confira-se nosso ensaio "The Rhetoric of Method" (MURARI PIRES 1998).
} 
Pelo que, em Valla, "a imparcialidade pode ser assegurada pelo fato de que ele não pertence a nenhum dos partidos em oposição: pode assim, por essa dimensão, reivindicar uma função notarial, pretender para o historiador a mesma confiança na imparcialidade e boa fé que comumente se atribui a um notário-escrivão" (FERRAú 1986, p. 272). Anthony Grafton, por sua vez, a corrobora incisivamente com todas as letras (GRAFTON 1997, p. 12, 50, 52).

Foi por ocasião do ensaio composto quando de sua participação nas The Menachem Stern Jerusalem Lectures, por inícios da década de 1990,31 que Carlo Ginzburg rearticulou o exercício hermenêutico porque outra vez se vinculasse a práxis historiográfica de Valla à de Tucídides, agora encadeando seus nexos desde a Declamatio, passando pelos Gesta, até finalizar pela tradução de Tucídides.

Seu ensaio define-se claramente como reação contra a intrigante epistemologia pós-modernista em moda nos anos 1970 e 1980, a qual, em sua implicância extrema voltada contra as orientações de cientificidade (dita) "positivista", quer a vetusta original, quer a renovada pelo "estruturalismo ciência" ("o positivismo burguês das ciências humanas) (GINZBURG 1999, p. 58), tendia a equiparar a escrita da história com a ficção literária, insistindo que tivesse a história uma dimensão de construto essencialmente retórico, razão porque a ideia de "prova" no ofício do historiador ficasse relegada a mera "ingenuidade positivista". Situando a inauguração desse "linguistic trend" e sua "turn toward rhetoric" nos textos de Roland Barthes, Ginzburg volta-se, em particular, contra as teses de Nancy Struever que, em sua obra de 1970 (The Language of History), moldava por essa perspectiva a hermenêutica da historiografia do humanismo quattrocentista, a qual estaria antes alicerçada em uma abordagem retórica "hostil à moderna noção de filologia.

A nova moda epistemológica, diz Ginzburg, não se deu conta do desvio de concepção de arte retórica que assumira. Era a modalidade de teorização ciceroniana que se afastava das argumentações precisas de prova enquanto fundamentação de verdade discursiva, antes operando sobre o jogo das emoções e paixões por que o orador "seduz os espíritos e convence as vontades" do público a que se dirige. Pelo contrário, a teorização aristotélica contemplava justamente o "escrutínio das provas" enquanto fundamento operatório essencial da arte retórica na apreensão racional da realidade referenciada pelo discurso (GINZBURG 1999, p. 63).

Ora, Lorenzo Valla na composição da célebre Declamatio, por ele próprio avaliada como sua "peça a mais retórica", ${ }^{32}$ instrumentara também sua argumentação em convergência com a operação da categoria das provas preceituadas por Quintiliano em sua Institutio Oratoria, especialmente as documentais (tabulae), assim finalizando a evidenciação de (ir)realidade histórica do fato, por princípios que remontam, na origem, à tradição teórica aristotélica (syngraphai). Na linhagem de pensamento retórico que encadeia Aristóteles a

\footnotetext{
31 "Lorenzo Valla on the Donation of Constantine", publicado na coletânea de History, Rhetoric and Proof (GINZBURG 1999, p. 54-70).

32 Carta de 31 de dezembro de 1443 a Aurispa.
} 
Quintiliano, e este a Valla, retórica e prova não são incongruentes entre si, antes, esta é o núcleo racional basilar daquela (GINZBURG 1999, p. 60-62).

Mas se, ao que avança a argumentação de Ginzburg, a retomada, via Quintiliano, da tradição aristotélica de arte retórica por Valla comporta verdadeiro paradoxo dada a "hostilidade" geral de seu pensamento em relação às teorias do estagirita, é decididamente esta contraposição que se impõe nos comentários por ele externados sobre a escrita da história nos Gesta Ferdinandi regis Aragonum. Polemizando contra a conceituação aristotélica de história consagrada na Poética, Valla, pelo contrário, (re)valoriza a história em termos da proposição justo de um saber voltado para a apreensão do "universal" na conduta humana. Sua visão da história era bem outra que a do estagirita, com Ginzburg expondo nestes termos as considerações do humanista romano: "escrever a história é difícil, diz ele, como podemos ver a partir da divergência entre testemunhos de determinado evento. Com o objetivo de estabelecer a verdade, o historiador precisa tanto acurácia quanto intuição, assim como qualquer juiz ou físico - uma dupla analogia particularmente intrigante" (GINZBURG 1999, p. 64). ${ }^{33}$

A melhor fundamentar a impressão deste seu último comentário acerca da "intriga da dupla analogia" da figura do historiador como que situada entre "juiz e médico", Ginzburg remete para: o artigo de Arnaldo Momigliano, assim justamente intitulado ("History Between Medicine and Rhetoric"), mais ensaios de sua autoria ("Clues" e "Il giudice e lo storico"), e ainda, completando a atualização de suas referências bibliográficas, para a obra de Paulo Butti de Lima ("L'inchiesta e la prova"). Que as alusões da reflexão de Ginzburg apontem a presença de concepções tucidideanas atuando na reflexão historiográfica de Valla ("Gesta") é óbvio já pela indução do paralelo de seus teores com a célebre declaração de "método" formulada por Tucídides (I, 22.3), e tanto mais confirmadas pelas referências bibliográficas anexadas por Ginzburg com esse propósito. Mas, curiosamente, o nome mesmo de Tucídides Ginzburg não externa, até aqui, em sua própria construção reflexiva!

$\mathrm{E}$, todavia, assim o faz tanto mais enigmaticamente no comentário com que fecha seu pensamento:

É difícil ver qualquer contradição entre essa ênfase no lado factual e antiquário da história e a afirmação, também feita por Valla na introdução de sua Gesta Ferdinandi, de que a retórica é a 'mãe da história'. A Retórica de Aristóteles, mediada por Quintiliano, deu a Valla a oportunidade para escapar das limitações da retórica ciceroniana. Não por acaso, em 1448, Valla começou sua tradução de Tucídides, um historiador que Cícero desprezou por sua obscuridade, apontando-o como um modelo negativo a ser evitado pelos oradores (Orator 9.30-32) (GINZBURG 1999, p. 64, grifos nossos). ${ }^{34}$

\footnotetext{
${ }^{33}$ No original: "Writing history is difficult, he said, as we can see from the divergences among eyewitnesses speaking of a given event. In order to ascertain the truth, the historian needs as much accuracy and insight as any judge or physician - a particularly intriguing double analogy".

${ }^{34}$ No original: "It is hard to see any contradiction between this emphasis on the factual, antiquarian side of history and the statement, also made by Valla in the introduction to his Gesta Ferdinandi, that rhetoric is "the mother of history. Aristotles' Rhetoric, mediated by Quintilian, gave Valla the opportunity to escape from the limitations of Ciceronian rhetoric. It is not by chance that in 1448 Valla started his translation of Thucydides, a historian whom Cicero had despised for his obscurity, pointing to him as a negative model for orators to avoid (Orator 9.30-32)".
} 
Que a estratégia discursiva de Ginzburg tenha clara teleologia polemizante, facilmente se percebe: a tessitura do argumento é catalisada pela contestação das teses daquela epistemologia em moda, que desqualificara a conjunção de práxis retórica com prova documental de realidade, entendendo-as como instâncias historiográficas inerentemente incongruentes. Justamente porque retórica, mas de fundamentação última aristotélica e não ciceroniana, a escrita da história opera categorias conceituais (prova, documento, testemunhos) e situa proximidades de ofício (juiz, médico) que referenciam a factualidade, isto é, o objeto real a que ela remete discursivamente. A imbricação do nome de Tucídides nessa tessitura argumentativa de modo a selar pelo prestígio de sua marca historiográfica o encadeamento consecutivo da obra valliana (Declamatio-Gesta-Tucídides), enquanto o passo a mais dado para a plena contundência crítica daquela teleologia, é, entretanto, estranhamente tortuosa.

No preciso momento reflexivo em que a indicação do nome de Tucídides era evidente e impositiva, Ginzburg o elide! Já quando, pelo contrário, o nomeia, mais confunde a argumentação "comprovadora" de sua tese do que decisivamente a plenifique. Que precisa implicação semântica tem aquele enigmático "it is not by chance"? O quê, decididamente, quer Ginzburg dizer com isso? A que sujeito, e sua correspondente proposição deliberativa, se refere essa ação para que fique negada sua "casualidade"? Se assim for entendido que tal sujeito seja Valla mesmo, como parece induzir a frase de Ginzburg, tem-se um contrassenso, porque a iniciativa da tradução não fora dele, mas a ele solicitada da parte de Nicolau V, sendo Valla, portanto, antes seu objeto! Se, pelo contrário, nos atemos ao entendimento suposto pelo efetivo sujeito referenciado pela frase de Ginzburg - ou o papa ou o cardeal Bessarion que (supostamente, ao que conjecturava o próprio Valla) recomendara os serviços do tradutor -, é a coerência do objeto transitivo da ação que fica comprometida, assim implicando que pelo menos um destes dois últimos, ou Nicolau ou Bessarion, estivesse ciente de que o pensamento e a obra de Valla fossem particularmente impregnados pela singular metodologia tucidideana, precisa razão porque se recomendava especialmente seu nome para aquela obra de tradução do historiador ateniense.

E, todavia, as intrigas dessa impregnação de ecos tucidideanos na fundamentação de sua metodologia crítica parece que não estivessem claras nem para o próprio Valla, a julgar pelos termos com que ele comenta sua tradução do historiador ateniense!

Os dizeres apologéticos com que o próprio Valla aprecia as virtudes da história de Tucídides, externados na carta em que apresenta sua tradução ao papa Nicolau $V$, apontam outros teores de excelência historiográfica que não são precisamente aqueles que Ginzburg assim ressalta como sendo as marcas de atenção porque Valla valorizasse especialmente a obra do historiador ateniense. A avaliação do desempenho historiográfico tucidideano ali configurada reproduz os parâmetros de louvor mais os delineamentos conceituais porque os antigos romanos o haviam memorizado, como, aliás, o declara o próprio Valla ao fazer, na conclusão de seu proêmio, expressa menção de que tal era o juízo "testemunhado pelos latinos". 
Por um lado, Valla afirma a excelência da obra tucidideana em termos que apelam essencialmente para a figuração de autoridade: o historiador ateniense realiza com tal virtuosidade os fundamentos da linguagem discursiva da escrita da história - "transparentes de seriedade, veemência e veracidade" - que firma nos leitores a convicção de que "tudo o que ele narra é verdade". Similarmente, Valla também a recomenda em termos das convenções que, desde tempos romanos, mais particularmente a partir de Políbio, foram seladas para o ofício do historiador, lembrando, em especial, que "aquele que escreve a história tenha visto as coisas de que fala respaldado por sua própria experiência atuante". Por quais consonâncias de supostos procedimentos "metodológicos" de crítica analítica Valla atestasse a "comprovação" de veracidade ou "realidade" dos fatos narrados por Tucídides, o humanista romano não explicita, antes silencia.

Por outro, as virtudes porque mais detidamente Valla celebra o primor da história tucidideana respeitam particularmente às figuras estilísticas que caracterizam sua narração, então diferenciadas pelo confronto com as de Heródoto. Tal juízo deriva, ainda outra vez, dos termos com que os antigos romanos haviam disposto tal paralelismo. Cícero (Orator 39) dissera que em Heródoto a escrita "fluía serena como as águas de um rio que corre sempre tranquilo". Valla ecoa sua apreciação, ainda mais a reforçando por imagens algo desdobradas, porque o elogia por estilo de "fluência uniforme e fácil, que desconhece qualquer aspereza, como um rio que corre docemente sempre igual, sem sobressaltos e sem ondulações". Diferente de Heródoto, o estilo de Tucídides, ao que dissera 40 Cícero, se caracterizava pela escrita antes "mais fortemente vigorosa, com suas descrições bélicas como que soando as trombetas da guerra". Valla reproduz os dizeres de Cícero, (re)formulando-os em sinonímias: escrita de "curso mais impetuoso, que ao falar das coisas da guerra parece ali estar presente, a emitir os sinais de combate". Às lembranças dos ditos ciceronianos, Valla então aduz o juízo de Quintiliano (Institutio oratoria X, 1.73) que mais o avaliza, agora expressamente citado e reproduzido em seu texto.

Tampouco os apontamentos marginais com que Valla ressaltou itens e aspectos da história tucidideana, que dele reclamaram algum zelo elucidador, indiciam uma especial atenção porque o humanista romano destacasse na obra do historiador ateniense aquela ordem de reflexão (modernamente) "metodológica" assimilada à que ele mesmo, Valla, similarmente operasse em suas razões de ajuizamento crítico de textos históricos. Nas indicações registradas junto aos célebres capítulos (ditos) "metodológicos" de Tucídides (I, 20-22), o foco do interesse de Valla marca que neles o ateniense polemizava contra Heródoto, assim apenas reproduzindo notícias encontradas nas escolias antigas. ${ }^{35}$ Também no desenvolvimento narrativo que Tucídides dá no livro VI à reflexão externada no livro I (capítulo 20) em que denunciava as tradições orais com que os atenienses equivocavam-se ao memorizar como tiranicídio o atentado contra Hípias e Hiparco, a atenção de Valla não manifesta ter-se impressionado com as virtudes de ajuizamento crítico do historiador ateniense

${ }^{35}$ Confiram-se os comentários de Marianne Pade (2000, p. 272, 276). 
porque este "indiciava" o exercício da tirania apenas por Hípias. Pelo contrário, o apontamento então assinalado por Valla conjectura como a razão do interesse de Tucídides por aquele episódio impressionante por sua narrativa e loquacidade amplificada, devia-se antes, ao que entende Valla, a aspectos de ordem pessoal, dado que sua família descendia da de Pisístrato. ${ }^{36}$

Tanto mais paradoxalmente perturbador, então, aventarmos que a leitura valliana de Tucídides reconhecesse cabalmente no historiador ateniense a consciência das manifestações daquela excelência de "método crítico" por que ele veio a ser posteriormente distinguido. ${ }^{37}$

Pelo que indiciam especialmente as partes submersas dos icebergs aristotélico-tucidideanos desprendidos por Ginzburg a enredar os nexos da historiografia retórica (e mutatis mutandis) da prova ${ }^{38}$ porque se diz o télos do conhecimento histórico em termos da álgebra da realidade verídica do fato histórico ("x did y ..."), emergem figurações discursivas que conjugam divinatio precipitada de associações conjecturais.

Pois, há nós falsos que (des)amarram os lances de malhas que tramam a rede argumentativa de Ginzburg.

\section{Referências bibliográficas}

ARISTOTE. Poétique, texte établi et traduit par J. Hardy. Paris: Les Belles Lettres, 1932.

AYA, Rod. The Third Man; or, Agency in History; or, Rationality in Revolution, History and Theory, Vol. 40, No. 4, Theme Issue 40: Agency after Postmodernism, Dec., 2001, p. 143-152.

BARTLETT, Robert. Witch Hunting. The New York Review of Books. New York: June 13,1991

BERTOZZI, Marco. Chasseurs d'indices. Quelques réflexions sur les formes de rationalité et les ruses de l'intelligence. In: THOUARD, Denis (éd.). L'interprétation des indices: enquête sur le paradigme indiciaire avec Carlo Ginzburg. Villeneuve d'Ascq: Presses Universitaires du Septentrion, 2007, p. 25-36.

\footnotetext{
36 "Ideo tot uerbis de hac re loquitur Thucydides quia ipse a Pisistrato fuit oriundus" (PADE 2000, p. 279). A provável fonte de que Valla deriva seu informe seria Marcelino, no entender de Fryde (1983, p. 90, 94). Este crítico, entretanto, ao acusar a falha de juízo exegético do humanista romano naquela: "Valla was guilty here of accepting uncritically an ancient authority who is most unlikely to have had any sources of information unknown to us", acaba (des)entendendo o comentário valliano, nele fazendo incidir sua própria ordem metodológica de análise documental, assim (con)fundida com o de Valla.

37 Confira-se, por exemplo, como a atenção do crítico moderno, Edmund B. Fryde (1983, p. 94), destaca como significativo que Valla acrescesse um apontamento, todavia apenas como glosa informativa traduzida de uma escolia, respeitante ao mito da morte de Itys, o que atestaria os ecos da consciência crítica tucidideana de ajuizamento histórico em Valla, quando, pelo contrário, naquelas passagens em que Tucídides expressamente externa seus posicionamentos acerca dessa problemática que opõe a história ao mito, Valla nada tenha assinalado no manuscrito de sua tradução! Sobre tal projeção operada pela crítica dos séculos XIX e XX que faz aderir em Valla (ou Leonardo Bruni) a configuração de modernidade "metodológica" antes atinente a esta (cons)ciência historiográfica atualizada, vejam-se nossos ensaios integrados em Modernidades Tucidideanas (MURARI PIRES 2007).

${ }_{38}$ Particularmente no que respeita aos desentendimentos das proposições da Retórica de Aristóteles aventados pelas articulações argumentativas de Ginzburg vejam-se as precisas análises de François Hartog (2011, p. 549-550). Confiram-se igualmente as análises de Carlos Eduardo de Almeida Ogawa em sua dissertação de Mestrado História, Retórica, Poética e Prova: a leitura de Carlo Ginzburg da Retórica de Aristóteles (2010).
} 
BLACK, Robert. Review: The Uses and Abuses of Iconology: Piero della Francesca and Carlo Ginzburg, Oxford Art Journal, Vol. 9, No. 2, 1986, p. 67-71.

BORGHESI, Francesco. Che cos'è um "problema storico"? Riflessioni metodologiche su Carlo Ginzburg e dintorni, in La struttura subatomica dell'esperienza. Questioni di teoria della storiografia, a cura di Barnaba Maj, Discipline Filosofiche, Anno XVI, numero 1, 2006, p. 109-126.

BURKE, Peter. Resenha crítica de Miti, emblemi, spie: Morfologia e storia, by Carlo Ginzburg. The Journal of Modern History, Vol. 62, No. 1, Mar., 1990, p. 108-111.

BUTTI DE LIMA, Paulo. L'Inchiesta e la Prova: immagine storiografica, pratica giuridica e retorica nella Grecia classica. Torino: Einaudi, 1996.

CANFORA, Luciano. Paradigma Indiziario e Conoscenza Storica. Dibattito su Spie di Carlo Ginzburg. Quaderni di Storia, Anno VI, numero 12, Iuglio/ Dicembre 1980, p. 3-54.

CARRIER, David. Resenha crítica de The Enigma of Piero de Carllo Ginzburg, Art Journal, Vol. 46, No. 1, Mysticism and Occultism in Modern Art, Spring, 1987, p. 75-79.

COHEN, Claudine. De la trace au tracé. Les empreintes humaines préhistoriques, in THOUARD, Denis (éd.). L'interprétation des indices: enquête sur le paradigme indiciaire avec Carlo Ginzburg. Villeneuve d'Ascq: Presses Universitaires du Septentrion, 2007, p. 211-224.

COHEN, Ralph. Introduction. New Literary History, Volume 34, Number 2, Spring 2003, p. IV-XIV.

DOJA, Albert. Creative misreading and bricolage writing: a structural appraisal of a poststructuralist debate, Revista Portuguesa de História do Livro e da Edição, Ano XI, n²2, 2007, p. 89-104.

DUMÉZIL, Georges. Science et politique. Réponse à Carlo Ginzburg, Annales. Histoire, Sciences Sociales, 40e Année, No. 5, Sep-Oct., 1985, p. 985-989.

ECO, Umberto. Chifres, Cascos, Canelas: Algumas Hipóteses Acerca de Três Tipos de Abdução. In: ECO, Umberto; SEBEOK, Thomas A. (orgs.). O Signo de Três: Dupin, Holmes, Peirce. São Paulo: Perspectiva, 1991, p. 219-243.

EGMOND, Florike; MASON, Peter. A Horse Called Belisarius, History Workshop Journal, No. 47, Spring, 1999, p. 240-252.

ELKINS, James. Why Are Our Pictures Puzzles? Some Thoughts on Writing Excessively, New Literary History, 27.2, 1996, p. 271-290.

GINZBURG, Carlo. Checking the Evidence: The Judge and the Historian, Critical Inquiry, Vol. 18, No. 1, Autumn, 1991, p. 79-92. . Lorenzo Valla on the "Donation of Constantine". In: History,

Rhetoric and Proof. Hanover; London: University Press of New England, 1999, p. 54-70. 
Carlo. Mitos, Emblemas, Sinais. Morfologia e História. Tradução de Federico Carotti. São Paulo: Companhia das Letras, 2001 [1989].

Carlo. Refléxions sur une hypothèse vingt-cinq ans après. In: THOUARD, Denis (éd.). L'interprétation des indices: enquête sur le paradigme indiciaire avec Carlo Ginzburg. Villeneuve d'Ascq : Presses Universitaires du Septentrion, 2007, p. 37-47.

GUIMARÃES, Manoel Luiz Salgado. Uma história da história nacional: textos de fundação. In: LIMA, Ivana Stolze; CERMO, Laura do (orgs.). História social da língua nacional. Rio de Janeiro: Edições Casa de Rui Barbosa, 2008, p. 393-413.

HAMOU, Philippe. "The Foosteps of Nature" : raisonnement indiciaire et "interprétation de la nature" au XVIIe. siècle. Quelques considérations historiques et épistémologiques. In: THOUARD, Denis (éd.). L'interprétation des indices: enquête sur le paradigme indiciaire avec Carlo Ginzburg. Villeneuve d'Ascq: Presses Universitaires du Septentrion, 2007, p. $189-210$.

HARTOG, François. Aristote et I'histoire, une fois encore, Critique, n769-770:

"Sur les traces de Carlo Ginzburg", juin-juillet 2011, p. 540-552.

. Conjoncture de fin de siècle: I'évidence en question. In:

Évidence de I'histoire: ce que voient les historiens. Paris: Éditions de I'École des Hautes Études em Sciencces Sociales, 2005, p. 215-235.

. L'oeil de Thucydide et l'histoire véritable, Poétique, 49, 1982, p. 22-30.

HERLIHY, David. Resenha crítica de Clues, Myths, and the Historical Method by Carlo Ginzburg, The Journal of Interdisciplinary History, Vol. 21, No. 3, Winter, 1991, p. 501-502.

JED, Stephanie. Proof and Transnational Rhetorics: Opening up the Conversation, History and Theory, Vol. 40, No. 3, Oct., 2001, p. 372-384.

MARTIN, John. Journeys to the World of the Dead: The Work of Carlo Ginzburg, Journal of Social History, Vol. 25, No. 3, Spring, 1992, p. 613-626.

MÉSSAC, Régis. Le "Detective Novel" et I'Influence de la Pensée Scientifique, Paris, Encrage, 2011.

MOLHO, Anthony. Carlo Ginzburg: reflections on the intellectual cosmos of a 20th-century historian, History of European Ideas, v. 30, 2004, p. 121-148.

MOST, Glenn. Philologie et interprétation indiciaire. In: THOUARD, Denis (éd.).

L'interprétation des indices: enquête sur le paradigme indiciaire avec Carlo Ginzburg. Villeneuve d'Ascq: Presses Universitaires du Septentrion, 2007, p. 59-74.

MURARI PIRES, Francisco. Mithistoria, São Paulo: Humanitas, 1999.

. Modernidades Tucidideanas. São Paulo: Edusp; Fapesp, 2007. 
A apoteose tucididana, Revista de História, primeiro semestre de 2012 (no prelo).

PAPE, Helmut. Searching For Traces: How To Connect the Sciences and the Humanities by a Peircean Theory of Indexicality, Transactions of the Charles S. Peirce Society: A Quarterly Journal in American Philosophy, Volume 44, Number 1, Winter 2008, p. 1-25.

PAYNE, Harry C. Resenha crítica de Clues, Myths, and the Historical Method by Carlo Ginzburg, The American Historical Review, Vol. 97, No. 4, Oct., 1992, p. 1176.

RANCIÈRE, Jacques. De la vérité des récits au partage des âmes, Critique, LXVIII n 769-770, Juin-Juillet 2011, p. 474-484.

ROVATTI, Pier Aldo. Dislocazzione della contraddizione e sapere dell'individuale, aut aut, 175-176, Gennaio-aprile, 1980, p. 27-40.

SCHUTTE, Anne Jacobson Schutte. Resenha crítica de Storia notturna de CCarlo Ginzburg, The Journal of Modern History, Vol. 64, No. 3, Sep., 1992, p. 575-576.

SIMON-NAHUM, Perrine. Resenha crítica de Le Fil et les Traces e Mythes emblèmes traces de Carlo Ginzburg, La vie des idées.fr, le 4 avril 2011. Disponível em: http://www.laviedesidees.fr/Carlo-Ginzburg-ou-lapolyphonie-de.html?lang=fr.

STRUEVER, Nancy S. Resenha crítica de Rediscovering History, edited by Michael S. Roth, MLN, 110.5, 1995, p. 1200-1204.

THOUARD, Denis. L'Enquête sur l'indice. Quelques préalables. In: (éd.).

L'interprétation des indices: enquête sur le paradigme indiciaire avec Carlo Ginzburg. Villeneuve d'Ascq: Presses Universitaires du Septentrion, 2007, p. 9-21.

TRUZZI, Marcello. Sherlock Holmes: Psicólogo Social Aplicado In: ECO, Umberto; SEBEOK, Thomas A. (orgs.). O Signo de Três: Dupin, Holmes, Peirce. São Paulo: Perspectiva, 1991, p. 59-88.

UZEL, Jean-Philippe. Pour une Sociologie de l'indice, Sociologie de I'Art, 10, 1997, p. 25-51.

VALERI, Valerio. Resenha crítica de The Cheese and the Worms de Carlo Ginzburg, The Journal of Modern History, Vol. 54, No. 1, Mar., 1982, p. 139-143.

VATTIMO, Gianni. L'ombra del neo-razionalismo. Note a "Crisi della ragione", aut aut, p. 175-176, Gennaio-aprile 1980, p. 19-26.

VEGETTI, Mario. Potenza dell'astrazione e sapere dei soggetti, aut aut 175-176, Gennaio-aprile, 1980, p. 5-18.

VOUILLOUX, Bernard. Soupçons sur l'indice : le syndrome de Benito, Textes \& Cultures, Volume XVI, n², 2011. Disponível em: http://www.revuetexto.net/index.php?id=2880.

ZAMBELLI, Paola. From Menocchio to Piero Della Francesca: The Work of Carlo Ginzburg, The Historical Journal, Vol. 28, No. 4, Dec., 1985, p. 983-999. 